\title{
Business Analysis of Computer Retailing from the Perspective of Electronic Information Technology
}

\author{
Wang Qiyao \\ School of Electronic Engineering, Xi'an University of Science and Technology, Xi'an, Shaanxi, China
}

Keywords: e-commerce; computer sales; business analysis; analysis

\begin{abstract}
: e-commerce is a tool that can effectively improve the competitiveness of the retail enterprises, which can make the enterprise's data information, process information and decisionmaking information, so as to improve the core competitiveness of the enterprise. Although the concept of e-commerce has entered China for many years, there are still problems in the development of e-commerce in China's retail industry. Most businesses cannot find a good mode of development. Some businesses use the e-commerce platform to expand the business layout. Trust crisis and so on all reflect that our retail industry still needs to calm down and think about Countermeasures in order to make good use of e-commerce to enhance competitiveness. Starting with the rapid development of electronic commerce, this paper analyzes the prospect of promoting the competitiveness of retail business with the positive impact of e-commerce and the existing problems in the process of using e-commerce to exploit the market in China's retail industry. Finally, it analyses the countermeasures to improve the competitiveness of China's retail industry by using electronic business affairs, and puts forward the construction of it for discussion.
\end{abstract}

\section{Introduction}

With the progress of society and the development of computer technology, especially the widespread popularization of micro computers, the application of computers has gradually permeated from the fields of scientific computing and real-time control to non numerical fields. In particular, database technology has become more and more perfect. The application of database management system for the development environment in office automation and business information management, its powerful function has been deeply recognized by people. It has entered the various fields of human society and plays a more and more important role. Computer management information system has been widely applied in various fields. The use of computer management information system can reduce manpower input, increase the efficiency of information processing, and reduce the difficulty of company management.

The information level of small and medium-sized enterprises and private enterprises in China has been in the primary stage. The statistics show that the proportion of enterprises which have really realized the high application of computers in the small and medium enterprises and private enterprises in the country is less than $10 \%$. However, with the increasing pressure of enterprise competition under the market economy and the continuous improvement of enterprise organization management concept and business process standardization, the information construction of small and medium enterprises and private enterprises has been continuously improved in recent years.

\section{Problems and Countermeasures}

(1) The information is closed. The information system of most enterprises is only a simple internal sales and storage management system, and the information system is aging. These enterprises have become "information isolated islands", which rarely have timely information exchange with customers and suppliers, so that the value of enterprise information has not been fully excavated and utilized, and a large amount of outward outward development has been lost. Business and the opportunity to attract more potential customers.

(2) The way of propaganda is backward and the current trend. At present, a large part of the 
retailer's way to expand the product popularity is still in the traditional advertising media. While relying on the e-commerce platform, it does not use the high-speed network information to provide the impetus to the expansion of the market. The network media plays an important role in the promotion of the competitiveness of the retailers. This new mode of publicity has brought huge profit space to the small and medium enterprises, which has low cost and wide range of radiation. If it does not catch the "sweet cake", it will be in a backward position in the whole competition trend.

(3) Distribution and payment lag. [3] distribution and payment are the common problems faced by most of the enterprises engaged in retail e-commerce. How to find a balance between improving the distribution time and controlling costs has always plagued all e-commerce.

Web site. In addition, payment is also a difficult problem, and the network security is always a sensitive problem. This problem is not well solved, and it will always bring psychological barriers to the customer's online payment.

(4) Blindly rely on the platform, ignoring the improvement of product quality. In the process of expanding the sales market, some retail e-commerce enterprises pursue the speed blindly. While selling products on the e-commerce platform, they do not take into account the quality and the promotion and optimization of after-sales service. The sales cannot reflect the quality of their products and bring many adverse effects to the consumers. It is also difficult to make the two consumption of control customers, and cannot really leave a stable customer. In the long run, this development model cannot improve the competitiveness fundamentally. At least at the present stage of development, if the retailer does not pay attention to the actual experience of the consumer and improves the actual value of its own products, it will finally pay a great deal. The big price.

The purpose of the application of the computer after service management system is to organize the internal resources of the company effectively and effectively to integrate the staff and service information flow in the company effectively. Through the application of the after sales service management system, we will standardize the business process and reasonable dispatching service system in the after-sales service process. Solve the problems brought by the old management mode in the aspects of planning, dispatching, maintenance and cost control, and the management of technical staff, so as to meet the requirements of information integration and high speed processing, and provide the basic guarantee for the increase of the business volume of the computer company.

The system construction will take the management thought process of the company computer after sale service as the guiding principle, combined with the actual application and actual situation of the computer company, as far as possible to follow the requirements of the regular management information system to carry out the service specification and design of the after-sales service. To solve the outstanding problems in the service process and to further improve the efficiency and the speed of production response, so as to improve the overall management, control, coordination and competitiveness of the company as a whole.

\section{Overall Design}

\subsection{Principles of system design}

The system strives to meet the needs of the actual work of the after-sale service of the computer company to the maximum extent, and gives full play to the practicality of the data storage processing in the service process, and considers the customer satisfaction and the improvement of the rate of after-sales service reaction as the most important point. As far as possible, the page is designed to be elegant and easy to operate.

The computer after-sales service management system is developed on the basis of B/S mode. The customer can perform satisfaction feedback operation only with the browser. It is more beneficial to the computer operator to use the remote database data for various management operations on the server side, and the result of the operation is sent to the client by the server end database. It is more convenient to show. This mode is easy to write and develop, and has low maintenance cost. Moreover, it has the advantages of fast transmission when data volume is not large. 


\subsection{System module design}

On the basis of the analysis of the system analysis and the analysis of the computer after service, the functional modules of the system are planned. The system can be divided into five modules: the administrator management module, the customer data module, the employee data module, the transaction distribution module and the customer satisfaction survey module.

Admin management module includes administrator management authority allocation, administrator password authentication, customer data module including customer definition, customer data, employee data module including employee definition and employee data; transaction distribution module includes fee recognition, fault alarm time limit, initial distribution transaction, re distribution transaction. The customer satisfaction survey module includes customer password verification, customer satisfaction feedback and customer satisfaction statistics.

\section{The Practical Countermeasures of the Retail Industry Using E-commerce Platform to Enhance Competitiveness}

\subsection{To optimize supply chain management}

With the chain, scale and cross regionalization of Chinese retail enterprises, in order to speed up the reaction speed of the enterprises to the market, realize the win-win situation with the suppliers, cultivate the loyal customers and optimize the supply chain management of the enterprises by electronic commerce is imminent. The supply chain management under the [4] e-commerce environment is a kind of activities and processes that use information technology to efficiently manage all the information of the enterprise, and to plan, coordinate, control and optimize the supply chain system. On the one hand, the supply chain management can be realized by means of electronic commerce. On the one hand, we can integrate the flow of each logistics, make the goods reach the final customers at the fastest speed, improve the customer satisfaction and loyalty continuously; on the other hand, through the coordination of supply chain management, the suppliers, dealers, transporters, and suppliers are communicated quickly. Banks and final consumers, and play the overall advantages of the supply chain, share information resources, by strengthening cooperation with suppliers to win cooperation advantages, help enterprises to reduce costs and environmental risks, and make full use of the existing capacity to obtain greater benefits, so as to maximize the overall supply chain strength and enhance the enterprise The core competitiveness of the industry.

\subsection{To expand the brand awareness and reputation by means of the network platform.}

Every enterprise needs to constantly expand its popularity and reputation in order to achieve great development. Expanding popularity and reputation is an important means for SMEs to enhance their competitiveness. [5] advertising is the first choice to expand popularity and reputation. But relying on television, newspapers, radio, outdoor and other traditional advertising media, it costs a lot. Many large scale enterprises put advertisements in traditional media, advertising accounts for over $30 \%$ of sales. If it is in the development of the market stage, the cost is even greater, in 1996, Wahaha pure water sales reached 100 million, in the bottled water market share of the first, but the advertising investment is nearly 50 million. Such advertising costs are absolutely limited in quantity and investment ratio, which is not affordable to SMEs. However, the price of online advertising is relatively low, and the continuous warming of social platforms such as microblog and WeChat has also provided a new way of publicity for small and medium retailers, which results in twice the result of half the effort. In the content of advertising and the effect of advertising, the network media will be more able to achieve direct and effective interaction and communication between the enterprise and the target customers than the traditional media.

\subsection{To make full use of electronic database}

Through effective electronic database operation, enterprises can obtain detailed sales information of customers, suppliers and sales points, and can use data mining technology to carry out sales 
analysis, commodity analysis, customer analysis, supplier analysis, inventory analysis and so on. On the one hand, it can help the manager get some market rules that deserve to be explored in the complicated data, better understand the status of the enterprise and the market, and make the correct decision; on the other hand, we can have a comprehensive understanding and mastery of the customer's demand information, and provide better personalized service for it in order to expand the sales of the product. Sale. Because of the use of the database as the core decision support and operation system, the retail enterprise can greatly improve the efficiency and efficiency of analysis and decision making, so that the enterprise can gain competitive advantage.

\section{Conclusion}

Retailers can expand their sales scale through the electronic business platform, but they must not forget the quality of products. In the evaluation system of e-commerce platform, the actual experience of consumers will affect the motivation of other consumers. The consumer itself is on the alert for online shopping, so providing high quality products and after-sales service is not only the focus of offline sales, but also the most critical point for online sales to maintain customers. In the sale of electronic business platform, eliminate false information, exaggerate propaganda, can not blindly pursue the growth of sales data. If the retailer grasps the actual experience of the consumer, it will gain the long-term advantage in the competition. At the same time, the high quality products will also enhance the brand image of the enterprise, which is of profound significance to the expansion of the whole market share.

\section{References}

[1] Arunkumar, N., Ram Kumar, K., Venkataraman, V. Automatic detection of epileptic seizures using permutation entropy, Tsallis entropy and Kolmogorov complexity [J]. Journal of Medical Imaging and Health Informatics, 2016, 6 (2):526-531.

[2] Fernandes, S.L., Gurupur, V.P., Sunder, N.R., Arunkumar, N., Kadry, S. A novel nonintrusive decision support approach for heart rate measurement [J]. Pattern Recognition Letters, 2017.

[3] Arunkumar, N., Mohamed Sirajudeen, K.M. Approximate Entropy based ayurvedic pulse diagnosis for diabetics - A case study [C]// Proceedings of the 3rd International Conference on Trendz in Information Sciences and Computing. 2011, 6169099:133-135.

[4] Yingyue Zhang, Ammar Algburi, Ning Wang, Vladyslav Kholodovych, Drym O. Oh, Michael Chikindas, and Kathryn E. Uhrich. Self-assembled Cationic Amphiphiles as Antimicrobial Peptides Mimics: Role of Hydrophobicity, Linkage Type, and Assembly State, Nanomedicine: Nanotechnology [J]. Biology and Medicine, 2017, 13(2):343-352. 